\title{
Correction to: A meta-analysis of factors driving the adoption of precision agriculture
}

\author{
Yeong Sheng Tey ${ }^{1} \cdot$ Mark Brindal $^{2}$
}

Published online: 13 October 2021

○ Springer Science+Business Media, LLC, part of Springer Nature 2021

\section{Correction to: Precision Agriculture https://doi.org/10.1007/s11119-021-09840-9}

The original version of the article contained a mistake in Table 1. It has been corrected in this correction.

The correct version of the Table 1 is given below:

The articles of Michels et al. (2020a) and (2020b) shown in the previously published version of Table 1 use different datasets rather than the same dataset as indicated by the note. The correct Table 1, reflecting a total of 19 studies (arising from 23 eligible articles) for the meta-analysis should appear as shown in the erratum. This correction does not affect the findings.

The original article can be found online at https://doi.org/10.1007/s11119-021-09840-9.

Yeong Sheng Tey

tyeong.sheng@gmail.com

1 Universiti Putra Malaysia, 43400 UPM Serdang, Selangor, Malaysia

2 The University of Adelaide, Urrbrae, South Australia 5064, Australia 


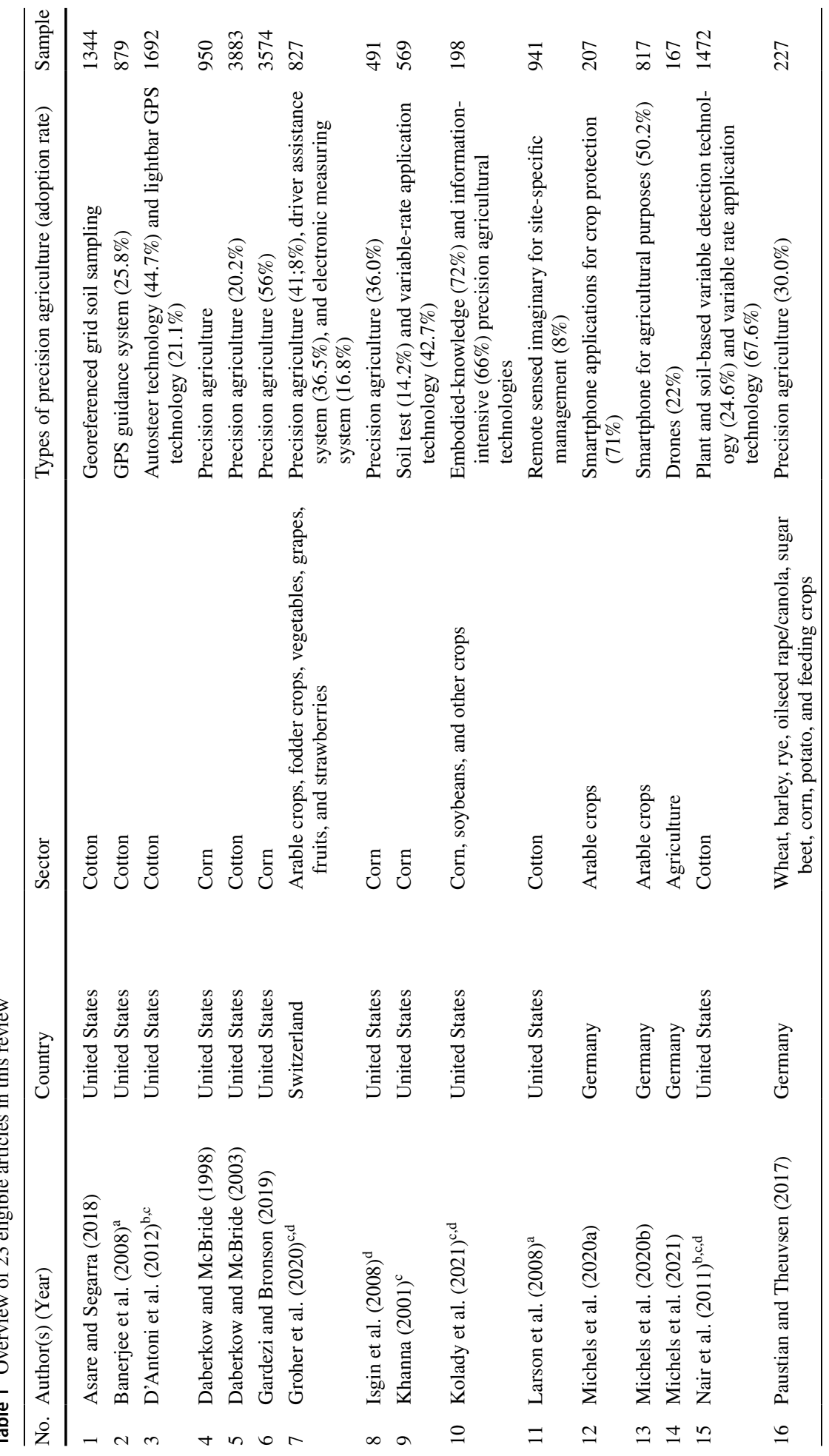




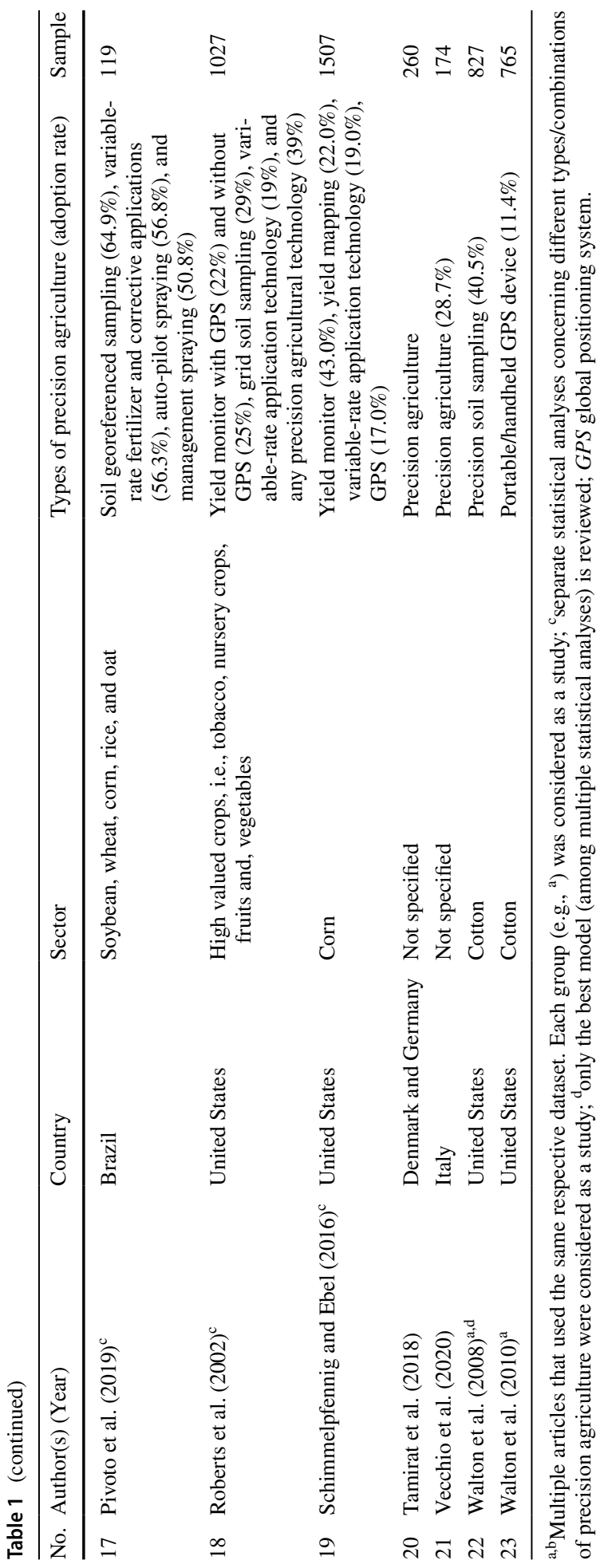


Publisher's Note Springer Nature remains neutral with regard to jurisdictional claims in published maps and institutional affiliations. 